\title{
Laboratory Column Test for Predicting Changes in Flow with Changes in Various Biofilter Mixtures
}

\author{
Redahegn K. Sileshi, Robert E. Pitt and Shirley E. Clark
}

\begin{abstract}
The performance of biofiltration and other infiltration systems in urban areas is affected by factors such as media particle size distributions and uniformity, and the degree of compaction during construction. This paper describes a series of controlled laboratory column tests conducted using various biofilter media to measure changes in flow with changes in the mixture characteristics, focusing on media density associated with compaction, particle size distribution (and uniformity), and amount of organic material (due to added peat). The results of the performance measurements of these mixtures were also verified using column tests (for different compaction conditions) of surface and subsurface soil samples obtained from Tuscaloosa, Alabama along with biofilter media obtained from Kansas City, North Carolina, and Wisconsin. The results of the full factorial analyses indicate that texture and uniformity of the media mixture have the greatest effect on the measured final infiltration rates of the media. The organic matter in the biofilter media does not have a significant effect by itself on the infiltration rate compared to the other factors (texture, uniformity and compaction). However the organic matter serves as a reservoir of nutrients and water in the biofilter media and increases water infiltration into the media.
\end{abstract}

Keywords: stormwater, biofilter, infiltration, compaction, amendments.

\section{Overview}

Bioretention systems are widely used in urban areas to reduce stormwater volumes, peak flows and stormwater pollutant loads which reach receiving waters. However, the performance of a bioretention system, and other infiltration devices, is affected by factors such as texture, structure, and the degree of compaction of the media during their construction. The soil-media mixture used in a bioretention system is central to determining water quality treatment and stormwater flow control performance. The premature clogging of filtration media by incoming sediment is a major problem affecting the performance of stormwater biofiltration systems in urban areas. Appropriate hydraulic characteristics of the filter media, including treatment flow rate, clogging capacity and water contact time, are needed to select the media and drainage system.

This paper describes a series of controlled laboratory column tests conducted, using various media, to predict changes in flow resulting from changes in the mixture. We focused on the media density associated with compaction, particle size distribution and uniformity, and the amount of organic material. The laboratory columns used in the tests contained various mixtures of sand and peat. The results of the predicted performances of these mixtures were also verified using column tests (for different compaction conditions) of surface and subsurface soil samples obtained from Tuscaloosa, Alabama infiltration test areas, bioretention media obtained from Kansas City biofilters, and standard samples of North Carolina biofilter media. Three levels of compaction were used to modify the density of the media layers during the tests: hand compaction, standard proctor compaction and modified proctor compaction.

Statistical analyses were performed to determine the effects of media texture, media uniformity, the organic content of the material, and compaction, and their interactions, on the flowrate through the bioretention media. Model fitting was performed on the time series plots to predict the flowrates through the mixtures as functions of these factors and their interactions.

\section{Introduction}

Understanding the physical and hydrologic properties of different bioretention media mixtures as well as their responses to compaction may increase the functional predictability of bioretention systems and thus improve their design (Pitt et al. 2002; Pitt et al. 2008; Thompson et al. 2008). The usual effects of soil compaction result in increased bulk densities, decreased moisture holding capacities, restricted root penetration, impeded water infiltration, and fewer macropore spaces needed for adequate aeration, all often leading to a significant reduction in infiltration (Gregory et al. 2006; Pitt et al. 2008; Thompson et al. 2008; Sileshi, Pitt et al. 2012; Sileshi, Pitt and Clark 2012). Infiltration tests, conducted on many different soils which had a wide range of texture and were representative of the great soil and parent-material group at 68 field sites throughout the United States, indicated that the infiltration rate decreases with increasing clay content and increases with increasing noncapillary porosity (Free et al. 1940). Premature clogging by silt is usually responsible for the early failures of infiltration devices, although compaction (during either construc-

Sileshi, R., R.E. Pitt and S. Clark. 2014. "Laboratory Column Test for Predicting Changes in Flow with Changes in Various Biofilter Mixtures." Journal of Water Management Modeling C373. doi: 10.14796/JWMM.C373.

() CHI 2014 www.chijournal.org ISSN: 2292-6062 
tion or use) is also a recognized problem (Pitt et al. 2002; Pitt et al. 2008).

Substantial reductions in infiltration rates were noted due to soil compaction, especially for clayey soils, during prior research (Pitt, Lantrip et al. 1999). Sandy soils are better able to withstand compaction, although their infiltration rates are still significantly reduced. Compaction was seen to have about the same effect as moisture saturation for clayey soils, with saturated and compacted clayey soils having very small effective infiltration rates (Pitt et al. 2008). Sandy soils can still provide substantial infiltration capacities, even when greatly compacted, in contrast to soils containing large amounts of clays that are very susceptible to compaction's detrimental effects. In a similar study that examined the effects of urban soil compaction on infiltration rates in north central Florida, Gregory et al. (2006) found a significant difference between the infiltration rates of a noncompacted pasture and a wooded area, despite similar textural classification and mean bulk densities.

Soil amendments (such as organic composts) improve soil infiltration rates and water holding characteristics, and add protection to groundwater resources, especially from heavy metal contamination in urban areas (Pitt, Clark and Field 1999; Pitt, Lantrip et al. 1999). Groundwater contamination problems were noted more often in commercial and industrial areas that incorporated subsurface infiltration and less often in residential areas where infiltration occurred through surface soil (Pitt, Clark and Field 1999; Clark et al. 2006). However, the pretreatment of stormwater runoff before infiltration can reduce many pollutants responsible for groundwater contamination, and also prolong the life of the infiltration device.

Compost has significant pollutant sorption and ion exchange capacities that can also reduce the potential contamination of groundwater from the infiltrating water (Pitt, Lantrip et al. 1999). However, newly placed compost amendments may cause increased nutrient discharges until the material is better stabilized (usually within a couple of years). In addition to flow control benefits, amended soils in urban lawns can also have the benefits of reduced fertilizer requirements and help control disease and pest infestation in plants (USEPA, 1997).

\section{Methodology}

\subsection{Bioretention Media}

Controlled laboratory column tests using various mixtures of media to predict changes in flow with changes in the mixture, focusing on media density associated with compaction, particle size distribution (and uniformity), and the amount of organic material were performed. The media examined included eight materials: four different sands, surface and subsurface soil from Tuscaloosa, Alabama bioinfiltration sites, Kansas City biofilter media, and standard biofilter samples from North Carolina. The sand media were obtained from local suppliers in Tuscaloosa, Alabama and Atlanta, Georgia. The column tests examined the different sand media mixed with different percentages of peat and each of the other four materials separately. Figure 1 shows four of the eight media, with the remaining four media being different filter sands.

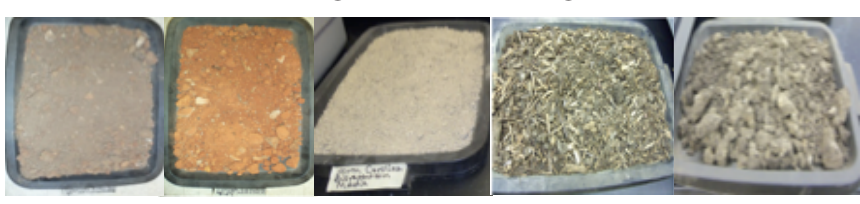

Figure 1 Media (from left to right): Tuscaloosa surface soil, Tuscaloosa subsurface soil, North Carolina biofilter media, Kansas City biofilter media from test site 1 and test site 2 .

The median size of the filter sand used in the sand-peat mixture ranged from $300 \mu \mathrm{m}$ to $2000 \mu \mathrm{m}$ and the uniformity coefficient ranged from 2 to 3.5. Figure 2 shows the particle size distribution plots for the various media used for the tests. The plot shows that both the North Carolina and Kansas City biofilter materials are relatively coarse, but the Kansas City biofilter material has a larger uniformity coefficient (uniformity coefficient $=D_{60} / D_{10}$, where $D_{60}$ is the particle size associated with the 60th percentile and the $D_{10}$ is the particle size associated with the 10th percentile).

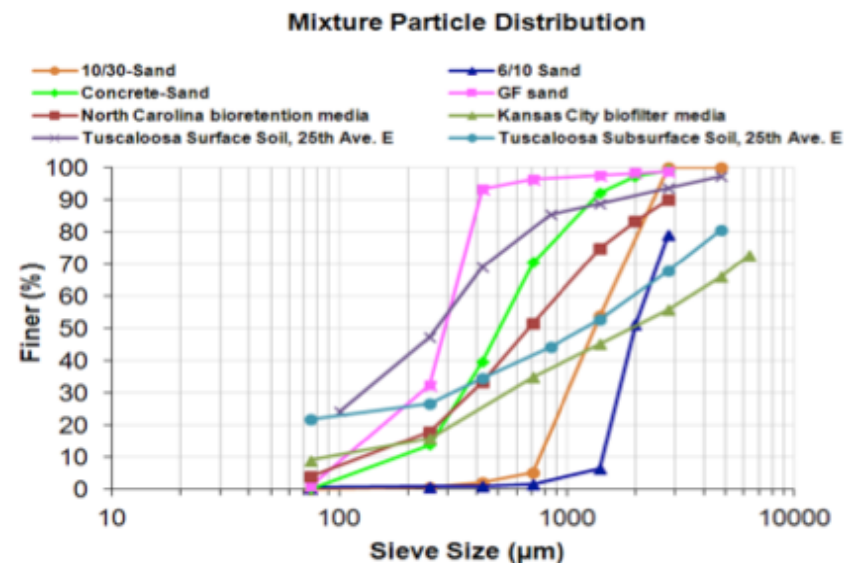

Figure 2 Particle size distributions of filter sands, Tuscaloosa surface and subsurface soil, and bioretention media obtained from Kansas City and North Carolina.

\subsection{Laboratory Column Tests}

The effects of different compaction levels on the infiltration rates through the media described in the previous section were examined during laboratory column testing in University of Alabama environmental engineering laboratories.

A 100 mm diameter PVC pipe (Charlotte Pipe TrueFit $100 \mathrm{~mm}$ PVC schedule 40 foam core pipe) purchased from a local building supply store in Tuscaloosa was used to construct the columns for these tests. In total 66 columns, each $0.9 \mathrm{~m}$ long, were constructed as shown in Figure 3. The columns were each filled with $\sim 5 \mathrm{~cm}$ of cleaned pea gravel purchased from a local supplier. To separate the gravel layer from the media layer, a permeable 
fiberglass screen was placed over the gravel layer and then filled with the different media listed in the previous section. The media layer was about $0.5 \mathrm{~m}$ thick. The bottom of the columns had a fiberglass window screen secured to contain the media.
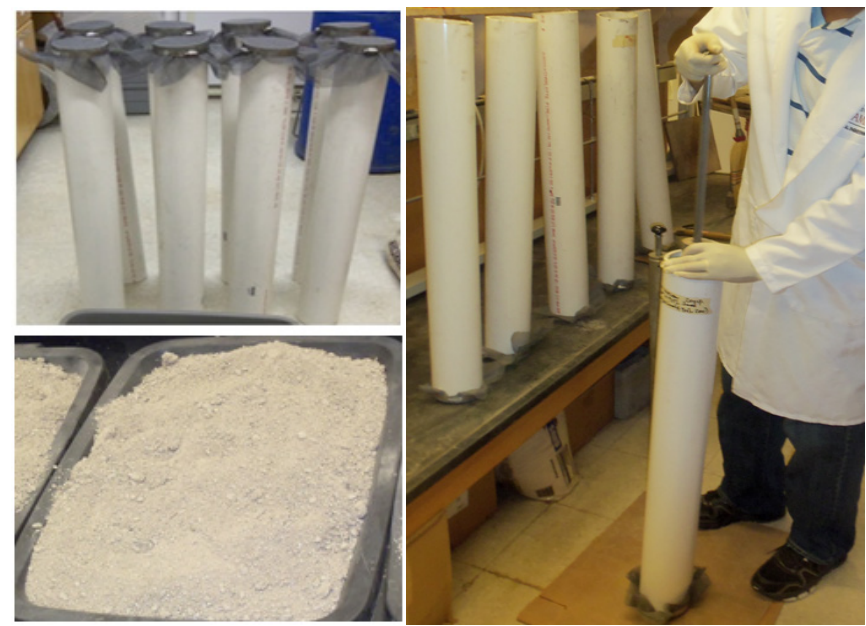

Figure 3 Lab column construction for infiltration tests (counterclockwise from top left): bottom of the columns secured with a fiberglass window screen, North Carolina bioretention media, and media compaction.

Three levels of compaction were used to modify the density of the column's bioretention media during the test (Figure 3): hand compaction, standard proctor compaction, and modified proctor compaction. Both standard and modified proctor compactions follow ASTM standard D 1140-54 (ASTM 1994).

The standard proctor compaction hammer is $24.4 \mathrm{kN}$ and has a drop height of $300 \mathrm{~mm}$. The modified proctor hammer is $44.5 \mathrm{kN}$ and has a drop height of $460 \mathrm{~mm}$. For the standard proctor setup, the hammer is dropped on the test media 25 times on each of three media layers, while for the modified proctor test, the heavier hammer was also dropped 25 times, but on each of five thinner media layers. The modified proctor test therefore results in much more compacted media, and usually reflects the most compacted soil observed in the field. The hand compaction is done by gently hand pressing the media material to place it into the test columns with as little compaction as possible, but with no voids or channels. The hand compacted media specimens therefore have the least amount of compaction. The densities were directly determined by measuring the weights and volume of the media material added to each column.

The infiltration rates through the bioretention media were measured in each column using municipal tap water. About $3.8 \mathrm{~L}$ of water was poured into each lab column at one time. The surface ponding depths in the columns ranged from $28 \mathrm{~cm}$ to $36 \mathrm{~cm}$. The freeboard depth above the media to the top of the columns was about $50 \mathrm{~mm}$ to $75 \mathrm{~mm}$. Infiltration rates in the bioretention media were determined by measuring the rates with time until apparent steady state rates were observed. Each experiment was repeated three times. The laboratory column setup for the infiltration measurements in the different media is shown in Figure 4.

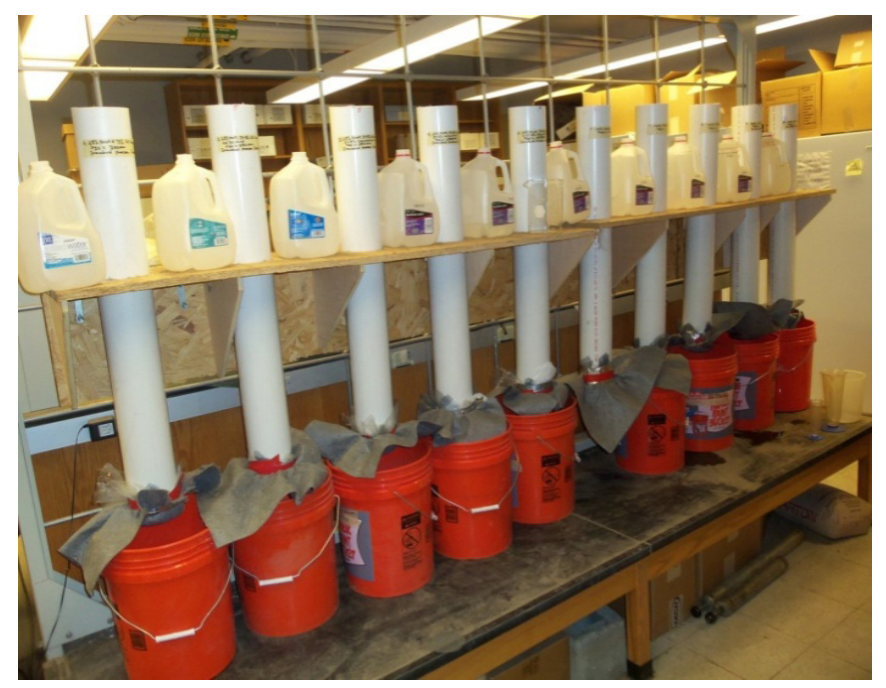

Figure 4 Laboratory column setup for infiltration measurements.

\section{Results and Discussions}

\subsection{Laboratory Infiltration Results Using Biofilter Media}

Infiltration data for different test trials using bioretention media from North Carolina and Kansas City biofilter media were fitted to Horton's equation by using multiple nonlinear regressions to estimate $f_{c}$ (the saturated soil infiltration rate) based on the observed data.

The estimated infiltration rates of saturated North Carolina bioretention media ranged from $2.1 \mathrm{~cm} / \mathrm{h}$ to $32.3 \mathrm{~cm} / \mathrm{h}$ for the hand compaction tests and $4 \mathrm{~cm} / \mathrm{h}$ to $5.6 \mathrm{~cm} / \mathrm{h}$ for modified proctor compaction tests. The estimated infiltration rates of saturated soils ranged from $0.9 \mathrm{~cm} / \mathrm{h}$ to $1.4 \mathrm{~cm} / \mathrm{h}$ for the hand compaction tests and $0.1 \mathrm{~cm} / \mathrm{h}$ to $0.9 \mathrm{~cm} / \mathrm{h}$ for modified proctor compaction tests using Kansas City biofilter media. Horton's plots of the different test trials, comparing different compaction conditions using North Carolina and Kansas City media are shown in Figures 5 and 6 respectively. 


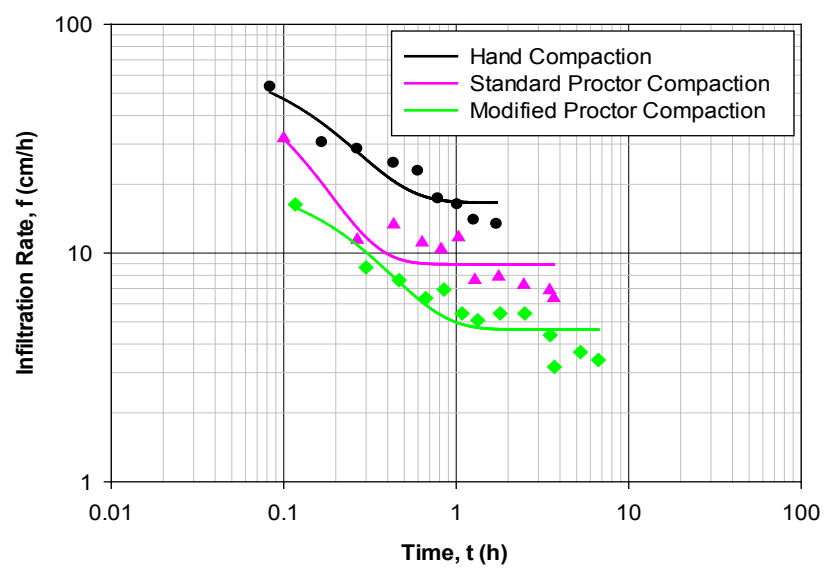

Figure 5 Laboratory infiltration test results using North Carolina media.

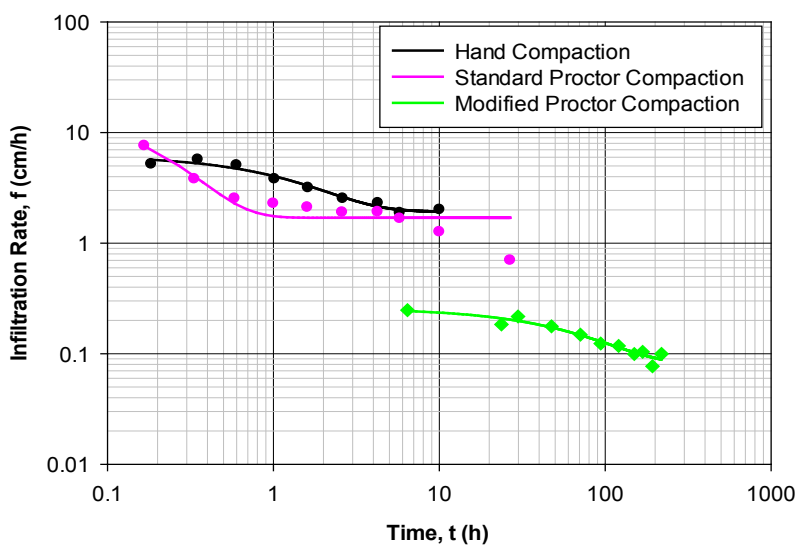

Figure 6 Laboratory infiltration test results using Kansas City media.

The saturated soil infiltration rates for hand, standard proctor and modified proctor compactions using North Carolina media are greater that the saturated soil infiltration rates through the Kansas City biofilter material for the three levels of compactions. Table 1 summarizes the laboratory column infiltration test results and the biofilter material properties. The median size ( $D_{50}$ is the particle size associated with the 50th percentile) and uniformity coefficient $\left(C_{u}=D_{60} / D_{10}\right.$, where $D_{60}$ is the particle size associated with the 60th percentile and the $D_{10}$ is the particle size associated with the 10th percentile) of the biofilter material are shown in Table 1.

\subsection{Laboratory Infiltration Results Using Sand- Peat Mixture}

Infiltration data for different test trials using different sand-peat mixtures were fitted to the Horton equation using multiple nonlinear regressions to estimate $f_{c}$ (the saturated mixture infiltration rate) based on the observed data. The average infiltration rates of the saturated mixtures indicated that the rates through the mixtures increased with increases in the percentage of peat. Horton plots of the different test trials are shown in Figures 7 and 8.

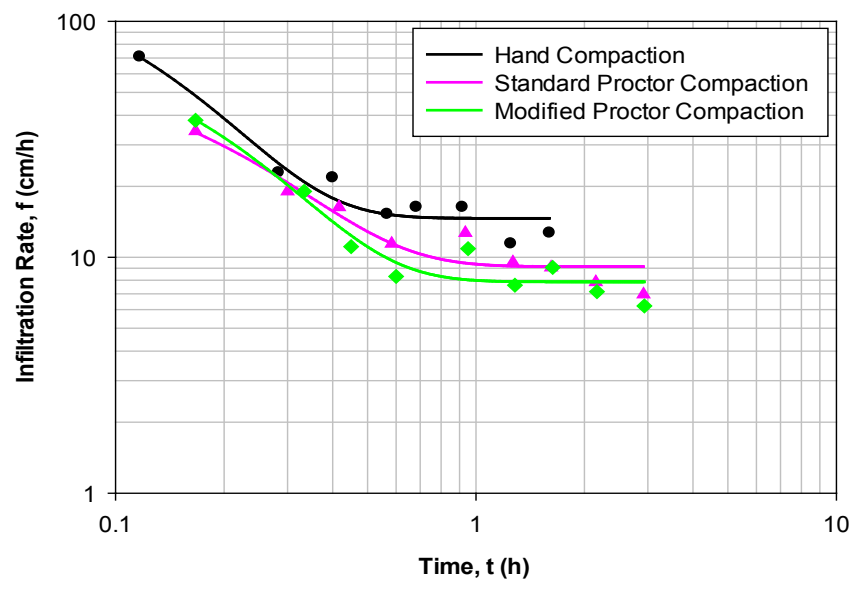

Figure 7 Infiltration measurements for $10 \%$ peat and $90 \%$ sand.

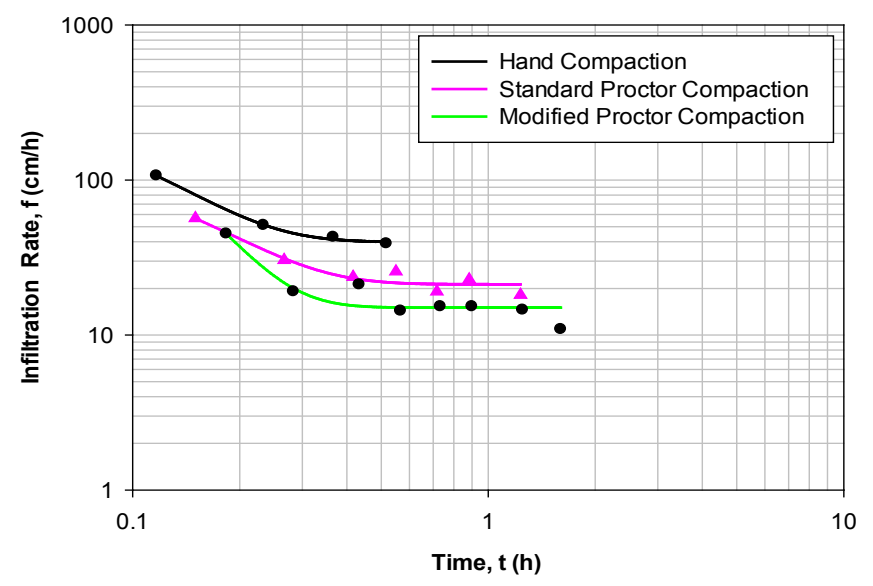

Figure 8 Infiltration measurements for $50 \%$ peat and $50 \%$ sand.

Table 1 Laboratory column infiltration test results.

\begin{tabular}{|c|c|c|c|c|c|c|c|}
\hline \multirow[b]{2}{*}{ Bioretention media } & \multicolumn{2}{|c|}{ Hand compaction } & \multicolumn{2}{|c|}{ Standard proctor compaction } & \multicolumn{2}{|c|}{ Modified proctor compaction } & \multirow[b]{2}{*}{$\begin{array}{l}D_{50^{\prime}} \mathrm{mm} \\
\text { and }\left(C_{u}\right)\end{array}$} \\
\hline & $\begin{array}{l}f_{c^{\prime}} \mathrm{cm} / \mathrm{h}, \\
\text { and }(\mathrm{COV})\end{array}$ & $\begin{array}{l}\text { Density, } \mathrm{g} / \mathrm{cm}^{3}, \\
\text { and (porosity) }\end{array}$ & $\begin{array}{l}f_{c^{\prime}} \mathrm{cm} / \mathrm{h}, \\
\text { and }(\mathrm{COV})\end{array}$ & $\begin{array}{l}\text { Density, } \mathrm{g} / \mathrm{cm}^{3}, \\
\text { and (porosity) }\end{array}$ & $\begin{array}{l}f_{c^{\prime}} \mathrm{cm} / \mathrm{h}, \\
\text { and }(\mathrm{COV})\end{array}$ & $\begin{array}{l}\text { Density, } \mathrm{g} / \mathrm{cm}^{3}, \\
\text { and (porosity) }\end{array}$ & \\
\hline \multirow{2}{*}{ Kansas City } & 1.40 & 1.0 & 1.61 & 1.13 & 0.34 & 1.12 & 1.9 \\
\hline & $(0.4)$ & $(0.36)$ & $(0.41)$ & $(0.15)$ & $(1.27)$ & $(0.25)$ & (39) \\
\hline \multirow{2}{*}{ North Carolina } & 18.8 & 1.24 & 10.2 & 1.34 & 5.1 & 1.36 & 0.7 \\
\hline & $(0.68)$ & $(0.34)$ & $(0.4)$ & $(0.3)$ & $(0.16)$ & $(0.3)$ & $(6)$ \\
\hline
\end{tabular}

Note: coefficient of variation ( $\mathrm{COV})$ is the ratio of the standard deviation to the mean. 
Figure 9 shows the infiltration rates $(\mathrm{cm} / \mathrm{h})$ through the sand-peat mixtures. The rates appear to increase with increases in the percentage of peat. Compaction did not significantly affect the infiltration rates for the mixtures having large amounts of sand and little peat. However, infiltration studies conducted previously indicated that compaction significantly affected typical soil infiltration rates having normal organic content, especially if high in fines (Sileshi, Pitt, Clark et al., 2012). Thus mixing the soil media with filter sand or peat improved the infiltration capacity of the media and also reduced the impact of compaction on the infiltration rates.

Four different sand media were used for the test series for full factorial tests and other analyses. Table 2 shows the sandpeat mixtures used during the tests. Up to fifteen replicates are available for each test series. The median sizes of the sand-peat mixtures ranged from $300 \mu \mathrm{m}$ to $1875 \mu \mathrm{m}$ and the uniformity coefficients ranged from 2 to 22 .

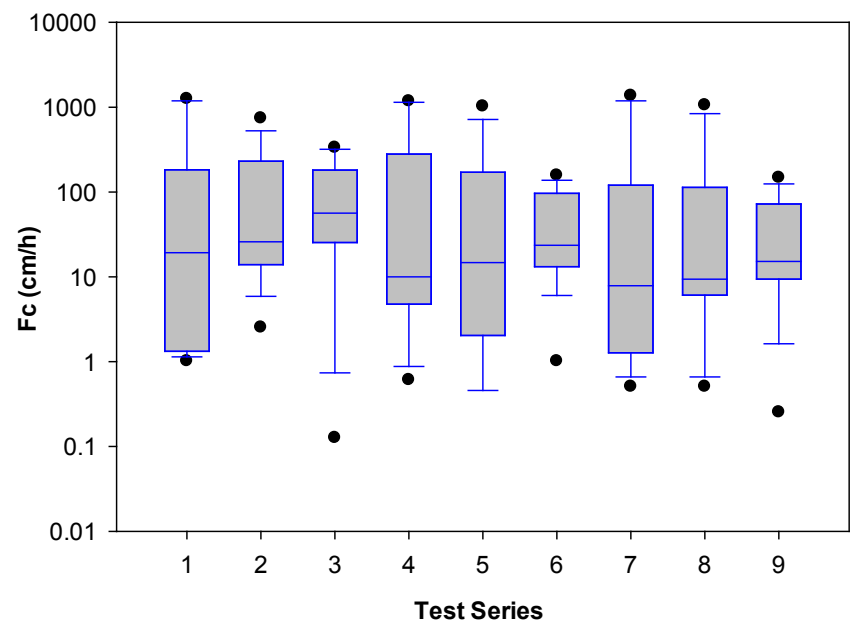

Figure 9 Box and whisker plots of the different test conditions, comparing different compaction conditions with varying amounts of peat amendments.

Table 2 Test mixture descriptions (fifteen replicates in each test series.

\begin{tabular}{cl}
\hline Data series & \multicolumn{1}{c}{ Mixture } \\
\hline 1 & $10 \%$ peat and $90 \%$ sand with hand compaction \\
2 & $25 \%$ peat and $75 \%$ sand with hand compaction \\
3 & $50 \%$ peat and $50 \%$ sand with hand compaction \\
4 & $10 \%$ peat and $90 \%$ sand with standard proctor compaction \\
5 & $25 \%$ peat and $75 \%$ sand with standard proctor compaction \\
6 & $50 \%$ peat and $50 \%$ sand with standard proctor compaction \\
7 & $10 \%$ peat and $90 \%$ sand with modified proctor compaction \\
8 & $25 \%$ peat and $75 \%$ sand with modified proctor compaction \\
9 & $50 \%$ peat and $50 \%$ sand with modified proctor compaction \\
\hline
\end{tabular}

\subsection{Statistical Analyses}

Statistical analyses were conducted to determine the effects of texture, uniformity, the amount of organic material, and compaction, plus their interactions, on the flowrate through the various mixtures of sand and peat to predict changes in flow, focusing on the media properties.

A complete two level and four factors $\left(2^{4}\right.$, with varying texture, uniformity, organic content, and compaction) factorial experiment (Box et al. 1978) was conducted to examine the effects of those factors, plus their interactions, on the flowrate through the various sand-peat mixtures. The factors studied, and their low $(-1)$ and high $(+1)$ values used in the calculations, are shown in Table 3. The complete data used in this factorial study is also summarized in Table 4, showing the $\log 10$ transformed $f_{c}$ rates for each experiment. Experiments were performed in replicates of three to fifteen for each of the infiltration measurements. Statistical methods are used to summarize the data and to provide an efficient method to analyze factor interactions on the flow rate.

Table 3 Laboratory column infiltration test results.

\begin{tabular}{lcc}
\hline \multicolumn{1}{c}{ Variable } & Low value $(-1)$ & High value $(+1)$ \\
\hline Median particle size of mixture $(\mathrm{T}), D_{50}(\mu \mathrm{m})$ & 500 & 1000 \\
Uniformity of the mixture $\left(C_{u}\right)$ & 4 & 6 \\
Organic content of the mixture $(0), \%$ & 10 & 25 \\
Compaction level $(C)$, hand/modified proctor & hand & modified proctor \\
\hline
\end{tabular}

The data analyses were performed using the statistical software package Minitab version 16 (Minitab 2010). Normal plots of the standardized effects, residual plots, main effects plots and interaction plots were prepared to examine the effects of the factors and to compare the significance of each effect. An analysis of variance (ANOVA) table was constructed to determine the significant factors and their interactions needed to best predict media flow performance. Statistical hypothesis tests using a $p$-value of 0.05 (95\% confidence) were used to determine whether the observed data were statistically significantly different from the null hypothesis.

Normal probability plots of effects are used to compare the relative magnitudes and the statistical significance of both main and interaction effects. These plots also indicate the direction of the effect. In Figure 10, the factor Texture and the interaction of Uniformity and Organic have positive effects because they appear on the right side of the plot. This means that when the low level changes to the high level of the factor, the response increases. In Figure 10, the interaction of Texture and Uniformity, Uniformity, Compaction, and the interaction of Uniformity and Compaction all appear on the left side of the plot, meaning that the factor has a negative effect. This indicates that when the low level changes to high, the response decreases. 
Table 4 Infiltration data used in full $2^{4}$ factorial designs.

\begin{tabular}{|c|c|c|c|c|c|}
\hline Case & Texture (T) & Uniformity (U) & Organic (0) & Compaction (C) & $\log (\mathrm{f})(\mathrm{cm} / \mathrm{h})$ \\
\hline $1 \mathrm{~A}$ & + & + & + & + & 0.07 \\
\hline $1 \mathrm{~B}$ & + & + & + & + & 0.40 \\
\hline $1 C$ & + & + & + & + & 0.97 \\
\hline $2 \mathrm{~A}$ & + & + & + & - & 1.60 \\
\hline $2 B$ & + & + & + & - & 1.31 \\
\hline $2 C$ & + & + & + & - & 0.33 \\
\hline $3 \mathrm{~A}$ & + & + & - & + & 0.90 \\
\hline $3 B$ & + & + & - & + & 0.71 \\
\hline $3 C$ & + & + & - & + & 0.40 \\
\hline $3 D$ & + & + & - & + & -0.99 \\
\hline $3 \mathrm{E}$ & + & + & - & + & -1.75 \\
\hline $3 \mathrm{~F}$ & + & + & - & + & -1.12 \\
\hline $4 \mathrm{~A}$ & + & + & - & - & 1.17 \\
\hline $4 \mathrm{~B}$ & + & + & - & - & 0.12 \\
\hline $4 C$ & + & + & - & - & 0.09 \\
\hline $4 D$ & + & + & - & - & 0.82 \\
\hline $4 \mathrm{E}$ & + & + & - & - & 0.91 \\
\hline $4 \mathrm{~F}$ & + & + & - & - & 0.98 \\
\hline $5 \mathrm{~A}$ & + & - & + & + & 2.17 \\
\hline $5 B$ & + & - & + & + & 2.04 \\
\hline $5 C$ & + & - & + & + & 1.86 \\
\hline $6 \mathrm{~A}$ & + & - & + & - & 2.54 \\
\hline $6 \mathrm{~B}$ & + & - & + & - & 2.57 \\
\hline $6 C$ & + & - & + & - & 2.45 \\
\hline $7 \mathrm{~A}$ & + & - & - & + & 3.10 \\
\hline $7 B$ & + & - & - & + & 3.06 \\
\hline $7 C$ & + & - & - & + & 2.78 \\
\hline $8 \mathrm{~A}$ & + & - & - & - & 3.14 \\
\hline $8 \mathrm{~B}$ & + & - & - & - & 2.81 \\
\hline $8 \mathrm{C}$ & + & - & - & - & 3.03 \\
\hline $9 \mathrm{~A}$ & - & + & + & + & 1.03 \\
\hline $9 B$ & - & + & + & + & 0.71 \\
\hline 9 & - & + & + & + & 0.68 \\
\hline $10 \mathrm{~A}$ & - & + & + & $\frac{T}{-}$ & 0.00 \\
\hline $10 \mathrm{~B}$ & - & $\begin{array}{l}+ \\
+\end{array}$ & + & - & $\begin{array}{l}1.03 \\
1.44\end{array}$ \\
\hline $10 C$ & - & + & + & - & 1.62 \\
\hline $11 \mathrm{~A}$ & - & + & - & + & 0.55 \\
\hline $11 \mathrm{~B}$ & - & + & - & + & 0.36 \\
\hline $11 C$ & - & + & - & + & 0.40 \\
\hline $11 D$ & - & + & - & + & -0.69 \\
\hline $11 \mathrm{E}$ & - & + & - & + & -0.90 \\
\hline $11 \mathrm{~F}$ & - & + & - & + & -1.12 \\
\hline $11 \mathrm{G}$ & - & + & - & + & -0.76 \\
\hline $11 \mathrm{H}$ & - & + & - & + & -0.68 \\
\hline 111 & - & + & - & + & -1.03 \\
\hline $11 \mathrm{~J}$ & - & + & - & + & -0.71 \\
\hline $11 \mathrm{~K}$ & - & + & - & + & -1.16 \\
\hline $11 \mathrm{~L}$ & - & $\begin{array}{l}+ \\
+\end{array}$ & - & + & -1.29 \\
\hline $11 \mathrm{M}$ & - & + & - & + & -0.06 \\
\hline $11 \mathrm{~N}$ & - & + & - & + & -0.08 \\
\hline 110 & - & + & - & + & -0.52 \\
\hline $12 \mathrm{~A}$ & - & + & - & - & $\begin{array}{l}0.02 \\
1.28\end{array}$ \\
\hline $12 \mathrm{~B}$ & - & + & - & - & $\begin{array}{l}1.20 \\
1.08\end{array}$ \\
\hline $12 C$ & - & $\begin{array}{l}T \\
+\end{array}$ & - & - & 1.21 \\
\hline $12 \mathrm{D}$ & - & + & - & - & 0.84 \\
\hline $12 \mathrm{E}$ & - & + & - & - & 1.16 \\
\hline $12 \mathrm{~F}$ & - & + & - & - & 0.78 \\
\hline $12 \mathrm{G}$ & - & + & - & - & 1.76 \\
\hline $12 \mathrm{H}$ & - & + & - & - & 1.47 \\
\hline 121 & - & + & - & - & 1.18 \\
\hline $12 J$ & - & + & - & - & 0.58 \\
\hline $12 \mathrm{~K}$ & - & $\begin{array}{l}+ \\
+\end{array}$ & - & - & 0.50 \\
\hline $12 \mathrm{~L}$ & - & + & - & - & 0.42 \\
\hline $12 \mathrm{M}$ & - & + & - & - & 0.90 \\
\hline $12 \mathrm{~N}$ & - & + & - & - & 0.91 \\
\hline 120 & - & + & - & - & 1.18 \\
\hline $13 \mathrm{~A}$ & - & - & + & + & 1.06 \\
\hline $13 B$ & - & - & + & + & -0.60 \\
\hline $13 \mathrm{C}$ & - & - & + & + & 0.98 \\
\hline $14 \mathrm{~A}$ & - & - & + & - & 1.86 \\
\hline $14 \mathrm{~B}$ & - & - & + & - & 1.72 \\
\hline $14 C$ & - & - & + & - & -0.90 \\
\hline $15 \mathrm{~A}$ & - & - & - & + & $\begin{array}{l}.00 \\
1.01\end{array}$ \\
\hline $15 B$ & - & - & - & + & 0.10 \\
\hline $15 \mathrm{C}$ & - & - & - & $\begin{array}{l}+ \\
+\end{array}$ & 0.71 \\
\hline $16 \mathrm{~A}$ & - & - & - & - & 1.34 \\
\hline $16 \mathrm{~B}$ & - & - & - & - & 0.10 \\
\hline $16 C$ & - & - & - & - & 0.01 \\
\hline
\end{tabular}

Normal Plot of the Standardized Effects (response is $\log (\mathrm{Fc})-\mathrm{cm} / \mathrm{h}$, Alpha $=0.05$ )

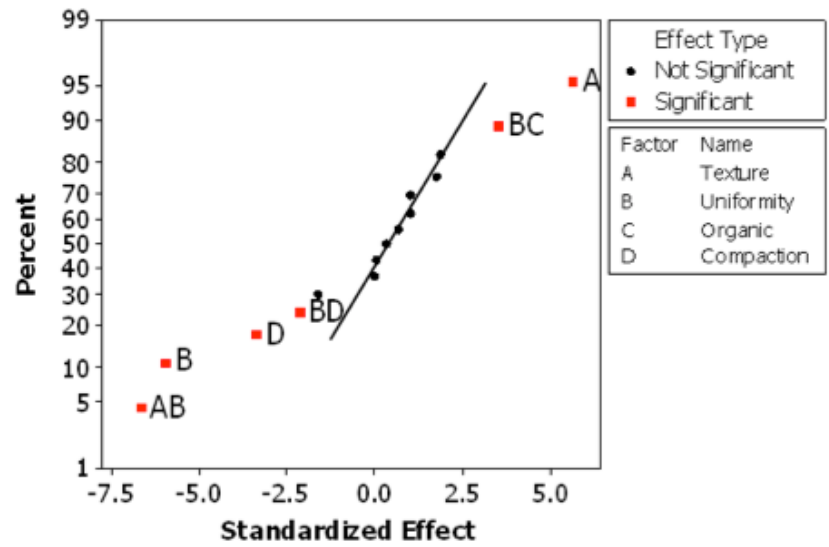

Figure 10 Probability plot to identify important factors

affecting the infiltration rate through a media mixture.

Figure 10 shows that Texture and the interaction of Texture and Uniformity have the highest effects on the measured infiltration rates followed by Uniformity, the interaction of Uniformity and Organic, Compaction, and the interaction of Uniformity and Compaction. The results of the factorial analyses are summarized in Table 5. Predicted residual sum of square (PRESS) is a measure of how the model fits each point in the design. As shown in Table 5 the PRESS and the error term of the factorial model are 40.1 and 0.62 respectively.

Table 5 Estimated effects and coefficients for $\log (f) \mathrm{cm} / \mathrm{h}$ (coded).

\begin{tabular}{|c|c|c|c|c|c|c|}
\hline Term & Effect & $\begin{array}{c}\text { Effect/ } \\
\text { Pooled SE }\end{array}$ & & SE Coef & $\mathrm{T}$ & $\mathrm{P}$ \\
\hline Constant & & & Coef & 0.082 & 13.910 & 0.000 \\
\hline $\mathrm{T}$ & 0.926 & 1.493 & 0.463 & 0.082 & 5.650 & 0.000 \\
\hline U & 0.966 & 1.558 & 0.483 & 0.082 & 5.900 & 0.000 \\
\hline 0 & 0.295 & 0.475 & 0.147 & 0.082 & 1.800 & 0.077 \\
\hline C & 0.547 & 0.882 & 0.273 & 0.082 & 3.340 & 0.001 \\
\hline$T^{*} U$ & 1.085 & 1.749 & 0.542 & 0.082 & 6.620 & 0.000 \\
\hline $\mathrm{T}^{*} 0$ & 0.261 & 0.421 & 0.131 & 0.082 & 1.590 & 0.116 \\
\hline$T^{*} \mathrm{C}$ & 0.116 & 0.186 & 0.058 & 0.082 & 0.700 & 0.483 \\
\hline$U^{*} 0$ & 0.580 & 0.936 & 0.290 & 0.082 & 3.540 & 0.001 \\
\hline$U^{*} \mathrm{C}$ & 0.347 & 0.559 & 0.173 & 0.082 & 2.120 & 0.038 \\
\hline $0^{*} \mathrm{C}$ & 0.056 & 0.090 & 0.028 & 0.082 & 0.340 & 0.736 \\
\hline$T^{*} U^{*} 0$ & 0.169 & 0.272 & 0.084 & 0.082 & 1.030 & 0.307 \\
\hline$T^{*} U^{*} C$ & 0.169 & 0.273 & 0.085 & 0.082 & 1.030 & 0.306 \\
\hline $\mathrm{T}^{*} 0^{*} \mathrm{C}$ & 0.014 & 0.022 & 0.007 & 0.082 & 0.090 & 0.932 \\
\hline$U^{*} 0^{*} \mathrm{C}$ & 0.310 & 0.499 & 0.155 & 0.082 & 1.890 & 0.064 \\
\hline$T^{*} U^{*} 0^{*} C$ & 0.001 & 0.001 & 0.001 & 0.082 & 0.010 & 0.995 \\
\hline
\end{tabular}

$S=0.620238 ; \quad$ PRESS $=40.1298 ; \quad$ Pooled $S E=0.62$.

$R-S q=76.82 \% ; \quad R-S q($ pred $)=61.00 \% ; \quad R-S q($ adj $)=71.21 \%$.

T: texture; U: uniformity; 0 : organic content; C: compaction.

According to Table 5, the significant factors and interactions that affect the long term infiltration rates are texture, 
uniformity of the mixture and compaction; interactions of texture and uniformity, interactions of uniformity and organic content of the material, and interactions of uniformity and compaction. Texture and uniformity had the greatest effects, but all those listed above were significant. Table 6 indicates that three way and four way interactions of the factors have no effect on the infiltration rates through the media.

Table 6 Analysis of variance for $\log \left(f_{c}\right) \mathrm{cm} / \mathrm{h}$ (coded units).

\begin{tabular}{|c|c|c|c|c|c|c|}
\hline Source & DF & SeqSS & AdjSS & Adj MS & $\mathrm{F}$ & $p$ \\
\hline Main Effects & 4 & 49.287 & 35.3973 & 8.8493 & 23 & 0.000 \\
\hline $\mathrm{T}$ & 1 & 13.483 & 12.2785 & 12.2785 & 31.920 & 0.000 \\
\hline U & 1 & 18.991 & 13.3735 & 13.3735 & 34.760 & 0.000 \\
\hline 0 & 1 & 1.612 & 1.2439 & 1.2439 & 3.230 & 0.077 \\
\hline $\mathrm{C}$ & 1 & 15.203 & 4.2854 & 4.285 & 11.140 & 0.001 \\
\hline 2-Way Interactions & 6 & 27.43 & 23.233 & 3.872 & 10.070 & 0.000 \\
\hline$T^{*} U$ & 1 & 16.634 & 16.8568 & 16.856 & 43.820 & 0.000 \\
\hline$T^{*} 0$ & 1 & 1.002 & 0.9763 & 0.976 & 2.540 & 0.116 \\
\hline$T^{*} \mathrm{C}$ & 1 & 1.409 & 0.1912 & 0.191 & 0.500 & 0.483 \\
\hline$U^{*} 0$ & 1 & 4.711 & 4.8266 & 4.827 & 12.550 & 0.001 \\
\hline$U^{*} \mathrm{C}$ & 1 & 3.408 & 1.7237 & 1.724 & 4.480 & 0.038 \\
\hline $0^{*} \mathrm{C}$ & 1 & 0.267 & 0.0442 & 0.044 & 0.120 & 0.736 \\
\hline 3-Way Interactions & 4 & 2.333 & 2.2803 & 0.570 & 1.480 & 0.219 \\
\hline$T^{*} U^{*} 0$ & 1 & 0.408 & 0.4077 & 0.408 & 1.060 & 0.307 \\
\hline$T^{*} U^{*} \mathrm{C}$ & 1 & 0.55 & 0.4096 & 0.409 & 1.060 & 0.306 \\
\hline $\mathrm{T}^{*} 0^{*} \mathrm{C}$ & 1 & 0.000 & 0.0028 & 0.003 & 0.010 & 0.932 \\
\hline$U^{*} 0 * \mathrm{C}$ & 1 & 1.375 & 1.373 & 1.373 & 3.570 & 0.064 \\
\hline 4-Way Interactions & 1 & 0.000 & 0.000 & 0.000 & 0.000 & 0.995 \\
\hline$T^{*} U^{*} 0^{*} \mathrm{C}$ & 1 & 0.000 & 0.000 & 0.000 & 0.000 & 0.995 \\
\hline Residual Error & 62 & 23.851 & 23.8511 & 0.3847 & & \\
\hline Pure Error & 62 & 23.851 & 23.8511 & 0.3847 & & \\
\hline Total & 77 & 102.902 & & & & \\
\hline
\end{tabular}

The main effects plots are useful to compare the magnitudes of the main effects. The main effect plots are obtained to examine the data means for the four factors. Figure 11 shows increases in infiltration rates occurred with increases in media texture and organic content, whereas infiltration rates decreased with increasing uniformity and compaction of the mixture.

Figure 12 depicts interaction plots which are used to interpret significant interactions between the factors. In the interaction plot, the lines in texture vs uniformity and in uniformity vs organic content are not parallel, indicating there exists an interaction between these factors. Figure 12 also shows that the lines in texture vs organic content and in texture vs compaction are approximately parallel, indicating a lack of interaction between the two factors. These interaction plots suggest that mutual interaction between these factors have negligible effect on the infiltration rates. The greater the departure of the lines from the parallel state, the higher the degree of interaction.

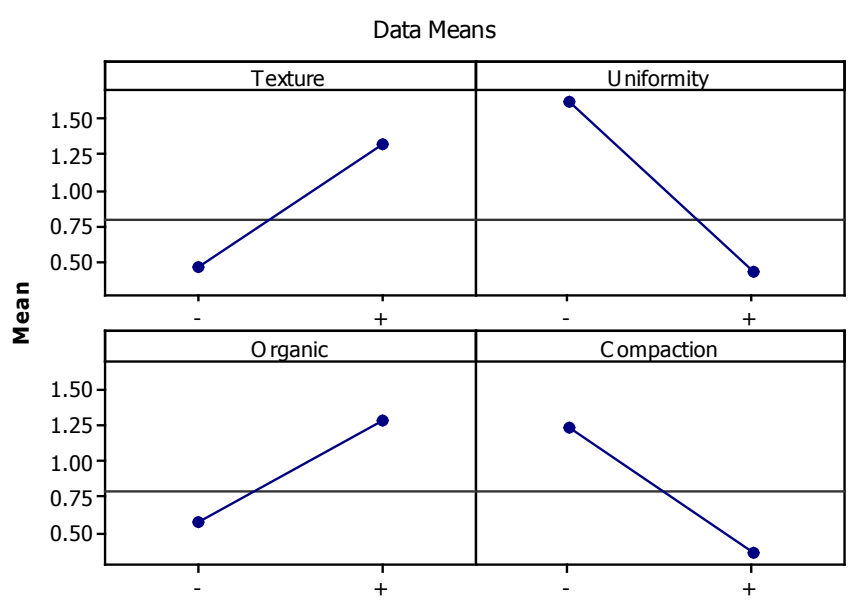

Figure 11 Main effects plot for the four factors.

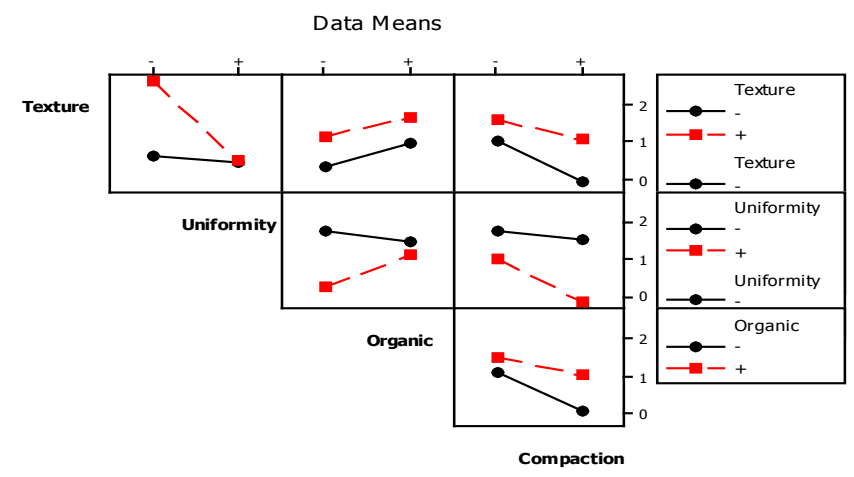

Figure 12 Interaction plot between different factors.

\subsection{Model Fitting}

The effects and half-effects of the significant effects (main effects and interactions) were used to predict the flow rate performance of various mixtures. Table 7 shows the matrix (table of contrasts) representing factors (texture, uniformity, organic content, and compaction) and their interactions. The results of the effects and half-effects are also shown in the table.

As noted previously, the significant factors and interactions that affect the responses are texture, uniformity, compaction, interactions of texture and uniformity, interactions of uniformity and organic content of the material, and interactions of uniformity and compaction. Those factors and interactions have to be included in the prediction equation. The parameters organic content, interactions of texture and organic content, interactions of texture and compaction, interactions of organic content and compaction, and all the three-way and four-way interactions of these factors, have negligible effect ( $p$-values greater than the chosen value of $a=0.05$ ) on the flow rate and a reduced model was created wherein these factors are ignored.

The prediction equation can be written in terms of the grand mean and half-effects, excluding the non-significant factors. 
Table 7 The results of the effects and half-effects.

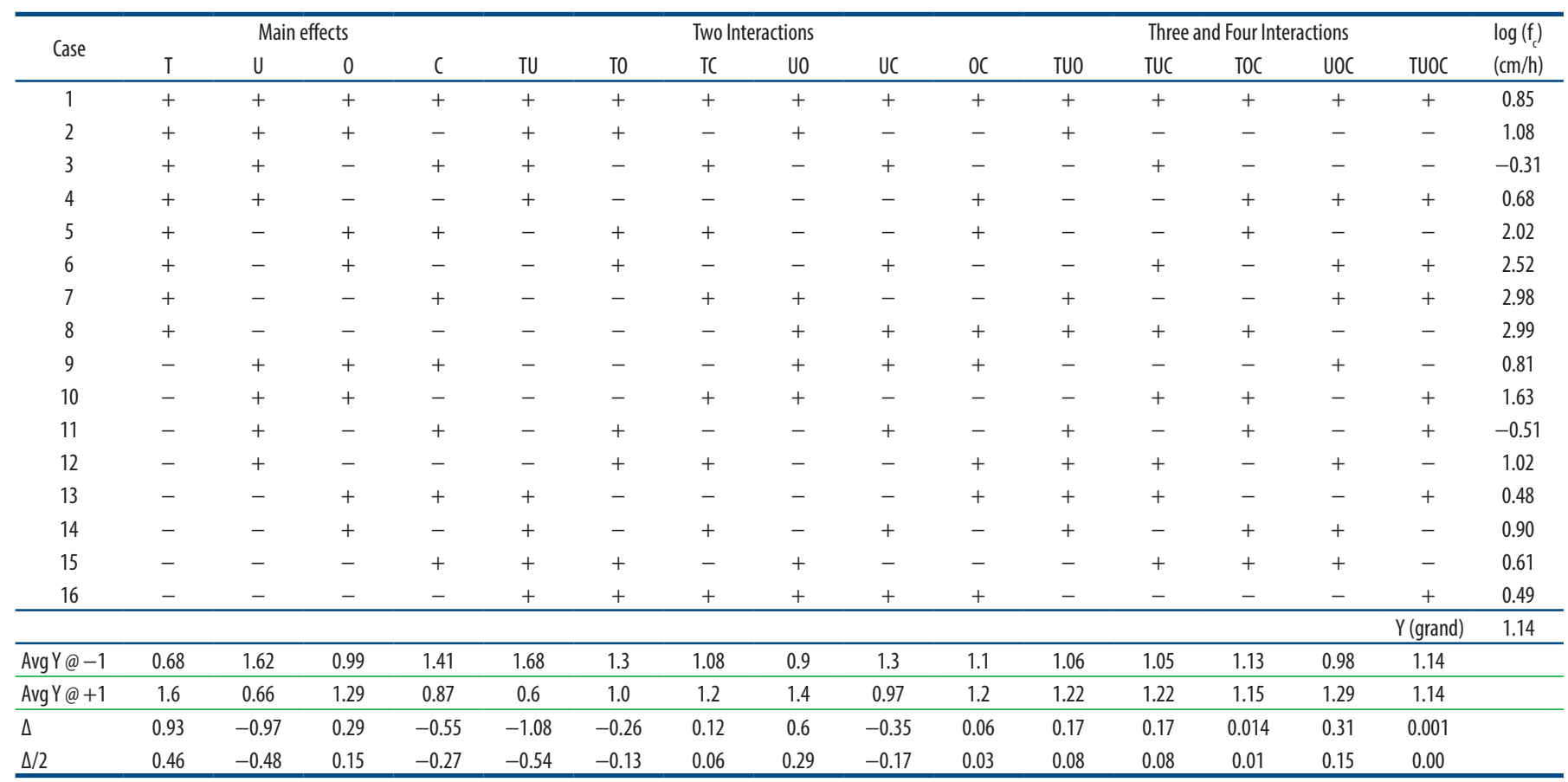

T: texture; U: uniformity; $\quad$ : organic content; C: compaction.

$\hat{y}=\bar{y}+\left(\frac{\Delta_{T}}{2}\right) T+\left(\frac{\Delta_{U}}{2}\right) U+\left(\frac{\Delta_{C}}{2}\right) C+\left(\frac{\Delta_{T U}}{2}\right) T U+\left(\frac{\Delta_{U O}}{2}\right) U O+\left(\frac{\Delta_{U C}}{2}\right) U C$ (1)

where:

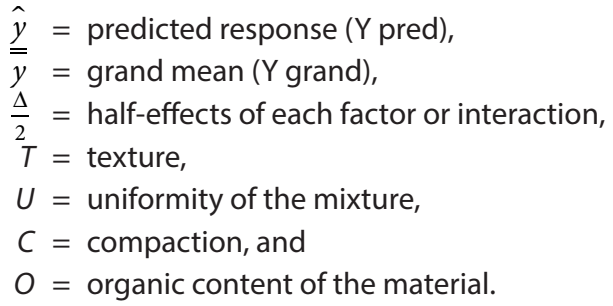

The final prediction equation is given as:

$\widehat{\log (y)}=1.14+0.46 T-0.48 U-0.27 C-0.54 T U+0.29 U O-0.17 U C(2)$

An ANOVA test was used to test the significance of the regression coefficients, which highly depends on the number of data observations. When only few data observations are available, strong and important relationships may not be shown to be significant, or high $R^{2}$ values could occur with insignificant equation coefficients. The data was evaluated by using the $p$-value (the probability of obtaining a test statistic that is at least as extreme as the calculated value if there is actually no difference; the null hypothesis is true). The independent variable was used to predict the dependent variable when $p<0.05$. A summary of statistical information about the model is also shown in Table 5. $R^{2}$ is a statistical measure of goodness of fit of a model whereas adjusted $R^{2}$ is a statistic that is adjusted for the number of explanatory terms in a model. The values of $R^{2}$ and adjusted $R^{2}$ for the model are $76.8 \%$ and $71.2 \%$ respectively. Predicted $R^{2}$ is calculated from the
PRESS statistic. The predicted $R^{2}$ statistic is computed to be $61.0 \%$. Larger values of predicted $R^{2}$ suggest models of greater predictive ability. This indicates that the model is expected to explain about $61.0 \%$ of the variability in new data. Figure 13 shows a scatterplot of the observed and fitted log $\left(f_{c}\right)$ values, indicating very good fits of the observed with the predicted $\log \left(f_{c}\right)$ values over a wide range of conditions.

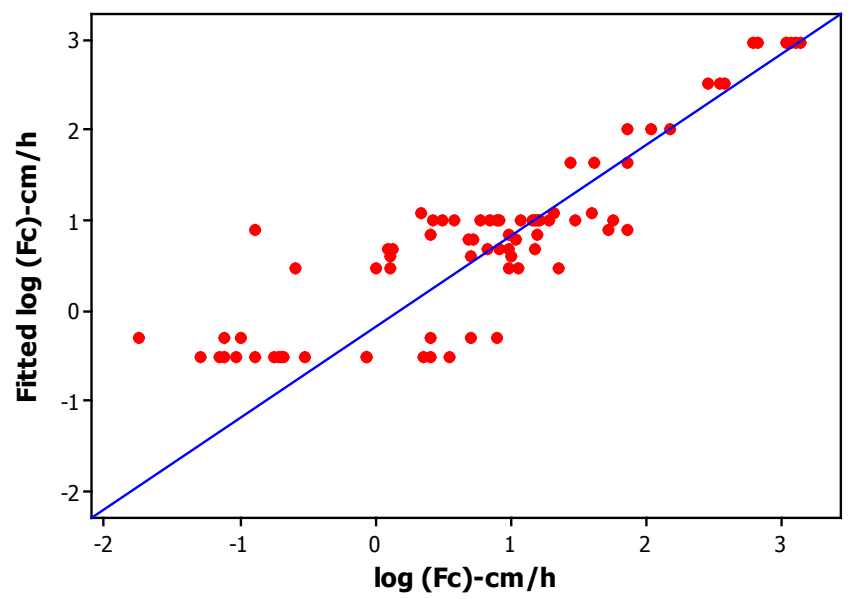

Figure 13 Observed vs fitted $\log \left(f_{c}\right)$ values.

Residual analyses were conducted to investigate the goodness of model fit. Residual plots were inspected to determine if the error term in the regression model satisfies the four assumptions (independent, zero mean, constant variance, and normally distributed). To check the constant variance assumptions, the 
plots of residuals vs the fitted values were inspected. To evaluate the normality of the residuals, normal probability plots and histograms of the residuals were also constructed. The Anderson-Darling (Anderson and Darling, 1954) test statistic was also calculated to check for normality. The normal probability plot of the residuals shown in Figure 14 shows that the fitted data is normally distributed (the Anderson-Darling test for normality has a $p$-value $>0.05$, so the data are not significantly different from a normal distribution for the number of observations available). The zero mean of the residuals assumption was checked by examining the descriptive statistics and graphs of the residual values vs fitted values and the residual values vs the order of the observations. To determine if the residuals were independent of each other, graphs of the residuals vs observation number were also examined.
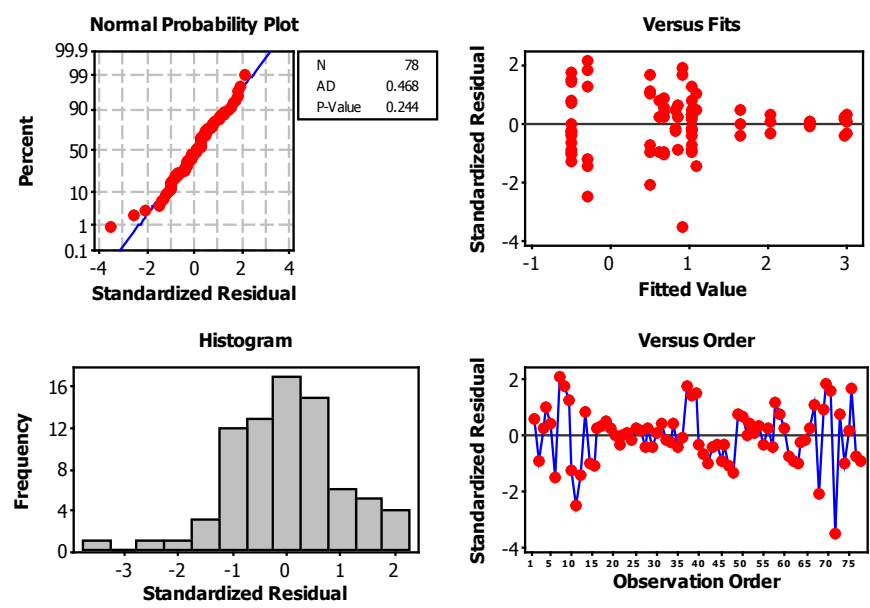

Figure 14 Residuals analysis plot.

The examination of the residual values vs fitted values of the data indicated that there was a greater spread in the residuals for the lower fitted values. The model residual histogram was approximately bell shaped; the residuals were normally distributed and had zero mean, and were independent of each other. Model improvements should therefore focus on conditions that had low infiltration conditions.

\section{Conclusions}

The laboratory compaction tests indicated that median particle size and media particle uniformity have the most significant effects on the infiltration rates, while the amounts of organic material had a smaller effect. Compaction did not significantly affect the infiltration rates for the media having large amounts of sand and few fines (silts and clays). Compaction significantly affected typical soil infiltration rates, however, especially for material having large amounts of clay.

The test results also indicated that the infiltration rates through all sand-peat mixtures columns were greater than the infiltration rates through only soil media for the three levels of compaction (modified proctor, standard proctor and hand compaction). However, mixing the soil media with filter sand or peat improved the infiltration capacity of the media and also reduced the impact of compaction on the infiltration rates. Soil compaction has dramatic effects on the infiltration rates of most underlying soils; therefore care needs to be taken during the construction of stormwater treatment facilities in urban areas to reduce detrimental compaction effects.

The results of the four factor factorial analysis indicated that media texture and the interaction of the texture and uniformity of the media mixtures have the highest effect on the measured infiltration rate, followed by uniformity, the interaction of uniformity and organic content, compaction, and the interaction of uniformity and compaction. The organic matter in the biofilter media does not by itself have a significant effect on the infiltration rate compared to the other factors (texture, uniformity and compaction). However the organic matter serves as a reservoir of nutrients and water in the biofilter media, aids in reducing compaction, and increases water infiltration into the media. The test results also indicate that the expected ranges of infiltration for the biofilter media ranged from $0.7 \mathrm{~cm} / \mathrm{h}$ to $20.4 \mathrm{~cm} / \mathrm{h}$, depending on the organic content and compaction of the media. The measured values during the laboratory tests agree with these predictions, ranging from $0.3 \mathrm{~cm} / \mathrm{h}$ to $19 \mathrm{~cm} / \mathrm{h}$ (the results for the organic content of these materials are not yet available).

\section{Acknowledgment}

The authors would like to thank the Department of Civil, Construction and Environmental Engineering, The University of Alabama, Tuscaloosa for financial support of this research.

\section{References}

ASTM (American Society of Testing and Material). 1994. Annual Book of ASTM Standards, Vol. 04.08. West Conshohocken, PA: ASTM.

Anderson, T. W. and D. A. Darling.1954. "A Test of Goodness-ofFit." Journal of the American Statistical Association 49:765-9.

Box, G. E. P., W. G. Hunter and J. S. Hunter.1978. Statistics for Experimenters. New York: Wiley.

Clark, S. E., K. H. Baker, J. B. Mikula, C. S. Burkhardt and M. M. Lalor. 2006. Infiltration vs Surface Water Discharge: Guidance for Stormwater Managers. Alexandria, VA: Water Environment Research Foundation. Project No.03-SW-4.

Free, G. R., G. M. Browning and G. W. Musgrave. 1940. Relative Infiltration and Related Physical Characteristics of Certain Soils. Washington, DC: U. S. Department of Agriculture. Technical Bulletin No. 729.

Gregory, J. H., M. D. Dukes, P. H. Jones and G. L. Miller. 2006. “Effect of Urban Soil Compaction on Infiltration Rate." Journal of Soil and Water Conservation 61 (3): 117-23.

Minitab. 2010. Minitab 16 Statistical Software. State College, PA: Minitab, Inc. www.minitab.com. 
Pitt, R. E., S.-E. Chen and S. E. Clark. 2002. “Compacted Urban Soils Effects on Infiltration and Bioretention Stormwater Control Designs." In Global Solutions for Urban Drainage (Proceedings of the Ninth Internatonal Conference on Urban Drainage), edited by E. W. Strecker and W. C. Huber, 1-21. Reston, VA: American Society of Civil Engineers. doi:10.1061/40644(2002)14.

Pitt, R. E., S.-E. Chen, S. Clark, J. Swenson and C. K. Ong. 2008. "Compaction's Impacts on Urban Stormwater Infiltration." Journal of Irrigation and Drainage Engineering 134 (5): 652-8.

Pitt, R. E., S. Clark and R. Field. 1999. “Groundwater Contamination Potential from Stormwater Infiltration Practices." Urban Water 1 (3): 217-36.

Pitt, R. E., J. Lantrip, R. Harrison, C. Henry and D. Hue. 1999. Infiltration through Disturbed Urban Soils and Compost-Amended Soil Effects on Runoff Quality and Quantity. Washington, DC: U. S. Environmental Protection Agency. EPA 600-R-00-016.

Redahegn K. Sileshi University of Alabama, Tuscaloosa, AL.

Robert E. Pitt University of Alabama, Tuscaloosa, AL.

Shirley E. Clark Pennsylvania State University, Harrisburg, PA.
Sileshi, R., R. E. Pitt and S. Clark. 2012."Assessing the Impact of Soil Media Characteristics on Stormwater Bioinfiltration Device Performance: Lab and Field Studies." In Proceedings of World Environmental and Water Resources Congress 2012: Crossing Boundaries, edited by E. D. Loucks, 3505-16. Reston, VA: American Society of Civil Engineers (ASCE). CD-Rom.

Sileshi, R., R. E. Pitt, S. Clark and C. Christian. 2012. “Laboratory and Field Studies of Soil Characteristics of Proposed Stormwater Bioinfiltration Sites." In Stormwater Symposium Proceedings 2012. Reston, VA: Water Environment Federation (WEF).

Thompson, A. M., A. C. Paul and N. J. Balster. 2008. “Physical and Hydraulic Properties of Engineered Soil Media for Bioretention Basins." Transactions of the American Society of Agricultural Engineers 51 (2): 499-514.

USEPA. 1997. Innovative Uses of Compost: Erosion Control, Turf Remediation, and Landscaping. Washington, DC: U. S. Environmental Protection Agency. EPA 530-F-97-043. 